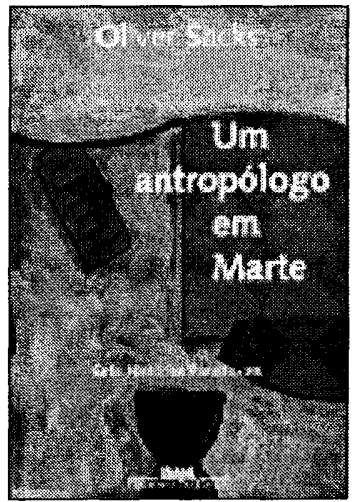

\section{Um Antropólogo em Marte ou os Paradoxos da} Saúde-Doença

Um Antropólogo em Marte - Oliver Sacks.

São Paulo: Companhia das letras, 1995.

331 páginas.

Maria Cecília de Souza Minayo

Departamento de Ciências Sociais, Escola Nacional de Saúde Pública, Fundação Oswaldo Cruz.
Pode parecer estranho que eu proponha a leitura desta obra justamente aos profissionais da saúde coletiva. Oliver Sacks não é nem um antropólogo nem um sanitarista. Esse inglês de Londres, residente em Nova York, é um neurologista e professor de neurologia clínica do Albert Einstein College of Medicine. Nem o título do livro diz respeito a ele próprio, como poderia parecer, uma vez que desenvolve a pretensão de compreender a lógica interna dos mais diferentes tipos de identidades pessoais de portadores de alguma deficiência neurológica ou cerebral. "Um Antropólogo em Marte" é expressão de uma das mais notáveis autistas, professora e Ph.D. em Ciências Animais, Temple Grandin, entrevistada por Sacks, para se referir aos grupos sociais que a cercam. Segundo ela, a dificuldade de entender as reações, as interaçōes, os sentimentos e expressôes dos ditos "normais" são de tal ordem, que ela se vê como uma "Antropóloga em Marte", ou seja, aquilo que nos parece estranho e bizarro em pessoas e grupos "diferentes" também seria estranho e bizarro para eles, em relaçào a nós. A dificuldade de entendimento é mútua.

Comentarei brevemente as sete histórias analisadas por Oliver Sacks antes de partir para uma reflexão que julgo essencial para nós, profissionais da saúde.

A primeira é a do pintor daltônico Jonathan I., assim transformado por um trauma provocado por acidente de carro, aos 65 anos. Esse trauma lesou a parte do seu cérebro especializada na percepção da cor. Sacks acompanha toda a trajetória de Jonathan, um pintor talentoso que, a partir do acidente, passou a ver o mundo em preto e branco. Registra todo o seu esforço para se adaptar e tirar partido da nova condição. É duplamente intrigante a ocorrência do daltonismo num artista para quem as cores tinham importância primordial, mais admirável, porém, the parece a capacidade dele de transformar a "deficiência" crucial de que foi acometido, em realizações talentosas de sua arte e nova visão do mundo.

Sacks acompanha também a estranha história de Greg, a quem denomina "o illtimo bippie", pela trajetória que começa com o brilho pessoal e a rotina de uma escola para a classe média em Queens, Nova York, passa pela negação da família, a vida alternativa e o uso de drogas no bairro do Village e termina encontrando refúgio num mosteiro Hare Krishna no Brooklyn. A vida religiosa que parecia provocar, no novo monge, iluminação e apaziguamento das inquietudes e mudanças, escondia, no entanto, um sério problema de saúde, detectado por intervençào médica, como tumor cerebral. Enca- 
minhado à cirurgia, Greg escapa da morte mas se torna cego, amnésico e "vazio". Por "vazio", Sacks entende a total incapacidade de Greg reter informações, realizar reflexôes, atribuir sentido, expressar emoções ou memorizar fatos e eventos atuais. $O$ autor desenvolve intensas consideraçōes solbre o grande desenvolvimento dos lobos frontais em humanos, sobre o papel dos sonhos, das vigílias e das fantasias. Comenta que Greg parou sua vida nos anos 60, de quando se lembra de conjuntos musicais, times de futebol $\mathrm{e}$ linguagem de época. O que mais impressiona, porém, no estudo de Sacks é sua capacidade de perceber em Greg não "um monstro", mas um ser humano capaz de criar a partir de seus sérios problemas de saúde. Como ele observa "ainda que como neurologista, eu tivesse que falar da síndrome de Greg, de seus 'déficits', não sentia que isso fosse adequado para descrevê-lo. Eu sentia que ele tinha se transformado em outro tipo de pessoa; que embora a lesão do lobo frontal tivesse, de certa forma, roubado sua identidade ou personalidade, também the deixara um tipo de identidade ou personalidade, ainda que de uma espécie estranha e primitiva" (pág. 74).

Mais fascinante ainda é a experiência narrada por Sacks com o Dr. Carl Bennett, portador da síndrome de Tourette. Essa síndrome se conhece pelos estranhos grunhidos, crispações, caretas, gestos, blasfêmias e xingamentos involuntários emitidos pelas pessoas que dela sofrem. Sem me deter aqui na sua descrição clínica, prefiro acompanhar o encantamento de Oliver pelo médico-cirurgião Dr. Bennett, morador da pequena cidade americana de Branford, amado e querido por seus clientes e respeitado pelos seus colegas de profissão, no pronto-socorro e no hospital local. Bennett, além de operar com perfeição, sem nunca ter cometido um deslize, dirige carro e pilota um pequeno avião particular. Sua "esquisitisse" lhe conferiu uma identidade e personalidade muito particulares, capazes de se manifestarem absolutamente convencionais durante as atividades profissionais. Os gestos bruscos, os tiques convulsivos, a mímica involuntária, as expressões compulsivas de xingamentos são inteiramente controladas na sala de cirurgia, por exemplo, manifestandose livremente nos momentos de descontração. Sacks em algum momento de seu estudo menciona que "estamos diante de algo de nível superior à mera repercussão rítmica, quase automática, dos modelos motores. Vemos um ato básico de encarnação ou interpretação, pelo qual, as habilidades, sensibilidades, a totalidade dos traços nêuricos de outro eu (grifo nosso) conquistam o cérebro, redefinem a pessoa, todo o seu sistema nervoso, durante toda a duração de seu desempenho" (pág. 113).

O caso de Virgil é também surpreendente. Cego descle tenra idade, aos 50 anos tornou-se noivo de uma moça que fez o impossível para conseguir uma cirurgia que lhe proporcionasse $\mathrm{O}$ dom da visão. Amy, a noiva, conseguiu em parte o que pretendera. Virgil voltou a ver. Porém a sua história nos permite uma profunda reflexão sobre o "enxergar" e o "ver". Quando Virgil abriu os olhos, depois de ter sido cego por tantos anos, não havia memória visual em que apoiar sua percepção e nem mundo algum de experiência e sentido esperando-o. Ele viu, mas o que viu não tinha coerência, seu cérebro não conseguia the dar sentido. "Nós que nascemos com a visão", diz o autor, "jamais poderemos imaginar tal confusão". Sacks caminha por toda a trajetória de sofrimento de Virgil na experiência de ver e não ver e nas frustrações de sua mulher Amy e conclui: "viu-se entre dois mundos, exilado em ambos - um tormento ao qual não parecia ser possível escapar. Mas aí veio a libertação, na forma de uma segunda e derradeira cegueira - uma ce- 
gueira que ele recebeu como dádiva. Agora, por fim, a Virgil é permitido não ver, escapar do mundo ofuscante e atordoante da visão e do espaço, para retornar a seu próprio e verdadeiro ser, o mundo íntimo e concentrado de todos os outros sentidos que havia sido seu lar em quase 50 anos" (pág. 164).

Outro caso interessante narrado por Sacks é o do artista plástico Franco Magnani que exilou-se, quando jovem, de sua terra natal, Pontito, pequena cidade da Toscana, na Itália, por ocasião da guerra. Denominado "Artista da Memória" Magnani tem uma capacidade obsessiva, fotográfica e infinita de retratar sua cidade (apenas ela), sob todos os ângulos, de forma recordatória e imaginativa. Este artista eidético, conforme Sacks, é ao mesmo tempo vítima e possuidor de um repertório de imagens, cujo poder é difícil conceber. Ele não está livre para ter equívocos de memória e nem para deixar de lembrar. Trata-se de uma memória patológica, com um poder de fixação, de fossilização ou de petrificação em plena atividade, marcada porém por uma responsabilidade cultural de recordar o passado e preservar seu sentido. Sacks, que acompanhou Magnani de São Francisco (onde vive e pinta compulsivamente) a Pontito, observando todas as suas ações e reações, conclui que se trata de um ser humano em profundo vazio interior. Situação essa criada pela guerra e pelo exílio, onde a arte da pintura transformouse num espaço externo de enumeração e recriação infinitas de um berço ao mesmo tempo idealizado e preservado. Todo esse entusiasmo inesgotável está a serviço de um projeto sem fim, porém sem introspecção e profundidade para além dele mesmo.

A penúltima história analisada por Sacks é a do autista Stephen Wiltshire, um garoto com prodigiosa capacidade de desenhar paisagens, ruas, edifícios, igrejas, castelos etc. Falando dos idiots savants o autor menciona que não se trata apenas de um sábio, mas de um prodígio. Nascido em Londres, filho de um funcionário da Companhia de Trânsito, pobre, esse rapaz hoje completa 22 anos. Depois de diagnosticado seu autismo, teve a felicidade de encontrar a compreensão de um professor e vários incentivadores que souberam valorizar mais seu talento que suas deficiências. E assim conseguiu se projetar, ter suas obras premiadas, suas capacidades estimuladas e ser hoje reconhecido como gênio. Desenvolveu também profundas habilidades musicais. Depois de acompanhar os passos, as reações, as vivências do talento no paradoxo das deficiências de Stıphen, Oliver concluiu: "suas limitações, paradoxalmente podem servir como forças também. Sua visão é valiosa, ao que me parece, precisamente por transmitir um ponto de vista maravilhosamente direto e não conceitualizado do mundo. Stephen pode ser limitado, esquisito, idiossincrático, autista; mas lhe foi permitido alcançar o que poucos de nós conseguimos, uma significante representação e investigação do mundo" (pág. 251).

Oliver Sacks termina sua obra com a história de Temple Grandin, a autista que lhe forneceu o título de seu trabalho. Professora da Colorado State University, gerente de seus próprios negócios, pesquisadora e conferêncista de renome, ela surpreende pela capacidade reflexiva sobre a problemática do autismo, mas sobretudo pela inteligência prática, pelo talento técnico, pelo forte poder de introspecção e relato. Mas seu poder essencial está na profunda sensibilidade para com o mundo animal e para a essencialidade do afeto e da compreensāo dos sentimentos do gado bovino e suíno. Temple surpreendeu a todos, numa recente palestra quando disse: "se pudesse estalar os dedos e deixar de ser autista, não o faria - porque então eu não seria mais eu. $O$ autismo é parte do que sou". E Sacks acrescenta: "É porque Temple acredita que o 
autismo possa ser associado com algo de valor que fica alarmada com a idéia de erradicá-lo (pág. 297).

Todos os sete relatos de Oliver Sacks são sobre pessoas reais que vivem hoje. No entanto, o mundo do senso comum, mas também da medicina moderna tende a confiná-los num texto sobre patologia. O que se torna comovente no livro de Sacks é a sua capacidade de colocar nossos preconceitos de ponta-cabeça, primeiro, valorizando o diferente; segundo, invertendo a relação de estranheza; e, em terceiro lugar, lançando novo olhar sobre o complexo e polissêmico mundo da saúde e da doença. Conforme afirma no prefácio do livro: "a imaginação da natureza é mais rica que a nossa; para mim, como médico, a riqueza da natureza deve ser estudada no fenômeno da saúde e das doenças, nas infinitas formas de adaptaçào individual com que organismos humanos, as pessoas, se reconstróem diante dos desafios e vicissitudes da vicla" (pág. 16).

Em outras palavras, Sacks quer mostrar que os distúrbios e as doenças podem ter um papel paradoxal de revelar poderes latentes, evolução e formas de vida que nunca seriam imaginados na ausência desses males.

Nesse sentido, a doença tem um poder criativo. Se por um lado, destrói caminhos precisos, força o sistema nervoso a buscar inesperados crescimentos e evolução.

Por isso, diz o autor, "sou levado a pensar se não seria necessário redefinir os conceitos de saíde/doença para vê-los em termos da capacidade do organismo de criar uma nova organização e ordem, adequada à sua disposição especial, e modificada segundo suas necessidades, mais do que em termos de uma 'norma' rigidamente definida" (pag. 18).

Ou seja, se a enfermidade geralmente corresponde a uma contração da vida, isso não é uma fatalidade, e quaisquer que sejam os problemas, as pessoas buscam a vida, não apenas a despeito de suas condições, mas por causa delas e até mesmo com sua ajuda.

Assim, a reflexão de Oliver Sacks vem a ser de imensa importância para todos os que trabalhamos no campo da Saúde. Sobretudo porque, sem grandes pretensões de ser um antropólogo em terra estranha, ele sinaliza aos que lidam nesse campo, para a necessidade de ultrapassar à mera tipificação de casos, procedimento tão presente na Clínica e na Epidemiologia, para se chegar ao mundo próprio e vivencial das pessoas. "O estudo da doença exige o estudo da identidade, os mundos interiores que os pacientes criam sob o impulso da doença. Mas a realidade dos pacientes, as formas como eles e seus cérebros constróem seu próprio mundo, não podem ser totalmente compreendidas pela observação do comportamento exterior" (ibid.).

E Sacks comenta Chesterston, através de seu detetive espiritual, quando diz: "quando um cientista fala de um tipo ou de um caso, nunca está se referindo a si mesmo, mas a seu vizinho, provavelmente mais pobre" (pág. 19).

Por compreender tudo isso, Oliver Sacks, um neurologista, tirou o jaleco branco e desertou do hospital e do laboratório, para pesquisar-compartilhar a vida de seus pacientes, como um neuroantropólogo em trabatho de campo, em visita às fronteiras distantes da experiência humana.

A neurologia e os estudos do cérebro hoje se tornaram áreas de ponta no campo do conhecimento. Sua contribuição para a visão mais ampliada de saúde não se discute. No entanto, causa admiração pensar que, na época do enaltecimento inconteste dos equipamentos e tecnologias de alto custo, o autor passe a exercitar sua reflexão e sabedoria no amplo laboratório da própria vida, onde a existência surpreende a cada dia, e da qual nunca sabemos o suficiente para nos tornarmos Ph.Ds. na promoção da saúde. 